\title{
Brugada Syndrome
}

National Cancer Institute

\section{Source}

National Cancer Institute. Brugada Syndrome. NCI Thesaurus. Code C142891.

A genetically heterogeneous condition characterized by complete or incomplete right bundle branch block accompanied by ST elevation in leads V1-V3. There is a high incidence of ventricular arrhythmia that may result in sudden death. 